\title{
Prosthodontic Rehabilitation of Maxillary Defect in a Patient with Mucormycosis
}

\author{
Satya Prakash M. ${ }^{1}$, Ashok V. ${ }^{2}$, Thiyaneswaran Nesappan ${ }^{3}$ Dhanraj M. Ganapathy ${ }^{4}$ \\ 1,2,3,4 Department of Prosthodontics, Saveetha Dental College, Saveetha Institute of Medical and Technical Sciences, \\ Saveetha University, Chennai
}

\section{INTRODUCTION}

Maxillofacial rehabilitation after accidents, surgical removal due to malignancy or congenital deformity is challenging, since it not only affects the patient function and aesthetics but also impairs the patient confidence in the society. Prosthodontic rehabilitation restores patient confidence, comfort along with function and aesthetics. Various prosthodontic treatment options are available. Selection of adequate prosthesis that suits the patient is of utmost importance. Fixed or removable prosthesis are selected based on the supporting structures. If the teeth or underlying bone are of poor quality or quantity, removable prosthesis is advised. Conventional complete denture therapy results in inadequate denture retention, stability \& patient satisfaction. ${ }^{1}$ The patient's confidence \& comfort in such cases would be compromised. However, the hybrid dentures could overcome the shortcomings of conventional complete dentures. Problems like loose dentures, loss of proprioception \& bone resorption can be resolved with hybrid dentures \& hence it is the last line of defence that successfully keeps patients from becoming edentulous. Studies indicate that there is inevitable resorption of residual ridge, following the loss of teeth. Ridges treated with hybrid dentures showed significant less vertical alveolar bone resorption than ridges with conventional complete maxillary and mandibular dentures. ${ }^{2}$ The rate of resorption depends on three factors; the character of bone, health of the individual and the amount and type of forces on the bone. Ten years of clinical investigation showed that weak teeth used as support for denture prosthesis not only remained in position but a few have regained a healthier status. ${ }^{3}$ Neil's Brill (1955) classified the dentures supported by the existing natural teeth that had characteristics of both a removable partial denture and a complete denture, were termed as Hybrid Prosthesis. ${ }^{4}$ This case report describes the prosthodontic rehabilitation of a patient after undergoing partial maxillectomy due to mucormycosis.

Rehabilitation of maxillofacial defect to an acceptable manner is challenging as it is related with psychological factors apart from function and aesthetics. A proper selection of prosthesis is utmost important to achieve this goal. The basic principles of any prosthetic design include preservation of the remaining natural tissues along with retention, stability, support, and aesthetics. Prosthodontic rehabilitation can be done either fixed or removable based on the supporting structures. If the hard tissue support is not adequate to withstand forces for fixed restoration, removable prosthesis are recommended. This clinical report describes maxillary rehabilitation with removable prosthesis in a compromised hard tissue support.
Corresponding Author: Dr. Satya Prakash M.

Department of Prosthodontics, Saveetha Dental College, Saveetha Institute of

Medical and Technical Sciences, Saveetha University, 162, Poonamallee High Road, Chennai 600077, Tamil Nadu, India.

E-mail: dr.sathyaprakash24@gmail.com

DOI: $10.14260 / \mathrm{jemds} / 2020 / 692$

How to Cite This Article:

Satya Prakash M, Ashok V, Nesappan T et al. Prosthodontic rehabilitation of maxillary defect in a patient with mucormycosis. J Evolution Med Dent Sci 2020;9(42):31633166, DOI: 10.14260/jemds/2020/692

Submission 16-07-2020,

Peer Review 10-09-2020,

Acceptance 16-09-2020,

Published 19-10-2020.

Copyright (C) 2020 Satya Prakash M. et al. This is an open access article distributed under Creative Commons Attribution License [Attribution 4.0 International (CC BY 4.0)] 


\section{PRESENTATION OF CASE}

A 26-year-old male patient reported to the Department of Prosthodontics, Saveetha Dental College \& Hospital, Chennai, with a chief complaint of difficulty in chewing and unaesthetic appearance for the past 16 months. Medical examination revealed that the patient had a history of kidney failure and got transplanted six years before. After 3 years of transplantation, rejection had taken place and at present he is undergoing dialysis. He had a history of mucormycosis and got treated 16 months before where partial maxillectomy was done (Figure 1). On oral examination, in maxilla the teeth present are $16,17,26,27$ and in mandible all teeth are present without any infection (Figure 2). Generalized gingivitis and fluorosis is seen. On radiographic evaluation, a thin bone is present in maxilla, bilaterally up to $2^{\text {nd }}$ premolar region.

Based on diagnosis, implant prosthesis was ruled out due to the immune status and the bone quantity of the patient. A removable prosthesis with a cast partial denture was planned with porcelain fused metal surveyed crowns in relation to 16 , 17, 26, 27. Diagnostic impression done using alginate impression material (Zhermack Tropicalgin) and preliminary casts made (Figure 3,4). Model analysis and surveying done. Special tray fabricated using polytray after blocking the undercuts, keeping $2 \mathrm{~mm}$ space on borders for peripheral tracing. After verification of special tray in the patients mouth for over extension, tray adhesive was applied on the special tray and peripheral tracing (Figure 5) was done using elastomeric impression material. (Polyvinyl siloxane). Definitive impression done with monophase (Dentsply Aquasil ultra) elastomeric impression material (Figure 6).

Abutment tooth preparation done in 16, 17, 26, 27 and wash impression done with light body elastomeric impression material (Virtual Ivoclar Vivadent) (Figure 7). Wax occlusal rim were fabricated on the master cast and jaw relation done and articulated. Cast partial framework design done using BEGO wax. Wax pattern for the metal coping done for the prepared abutment teeth and casting done. After trimming the metal coping, ceramic layering done leaving metal rest seat for the direct retainer in the cast partial denture (Figure 8). Wax teeth trial done intraorally to verify aesthetics and occlusion (Figure 9). Cast partial framework fit was verified (Figure 10).

Cast partial denture was characterized and processed using IVOCAP (Ivoclar). Trimming and polishing done, and tooth characterization performed (Figure 11). Porcelain fused metal crowns were luted using glass ionomer cement (Hybond Gic Shofu) and cast partial denture was inserted (Figure 12a, $12 \mathrm{~b}, 12 \mathrm{c})$. The border extensions of the prostheses, function, aesthetics, and occlusion with the prostheses on patient were evaluated. The final prosthesis demonstrated satisfactory retention, stability, support and patient satisfaction.

Instructions regarding maintenance of oral hygiene and prostheses were given. Patient was recalled for routine checkup after three months and six months durations to evaluate abutment teeth condition as well as general and oral health. No signs of secondary caries in abutment teeth and other relevant signs or symptoms observed. Patient was completely satisfied with the prosthesis (Figure 13)
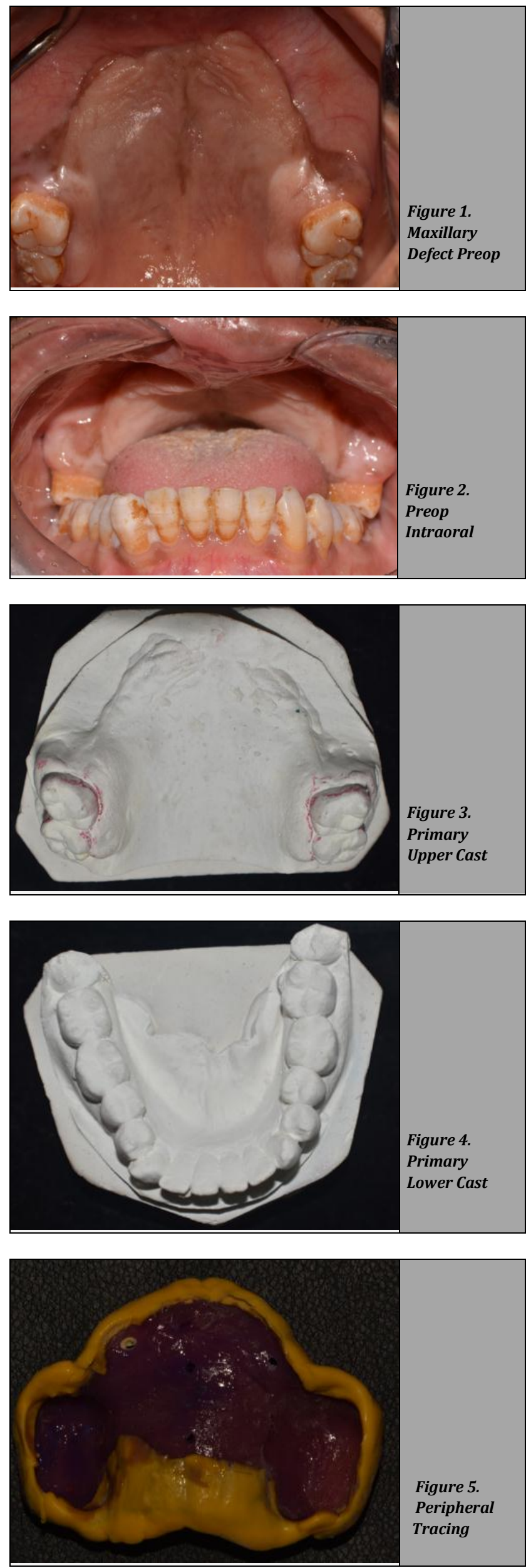

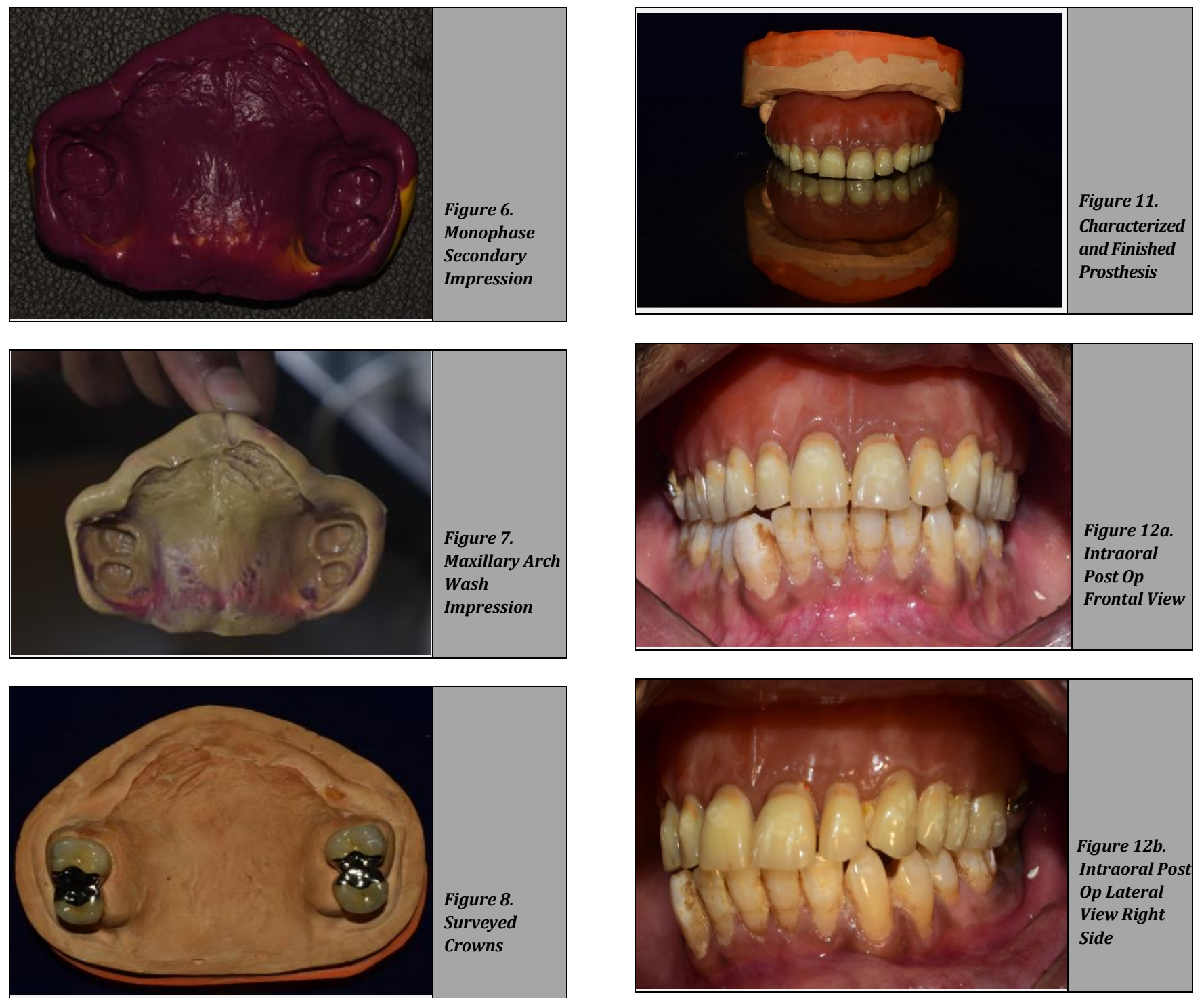

Figure 8.

Surveyed

Crowns
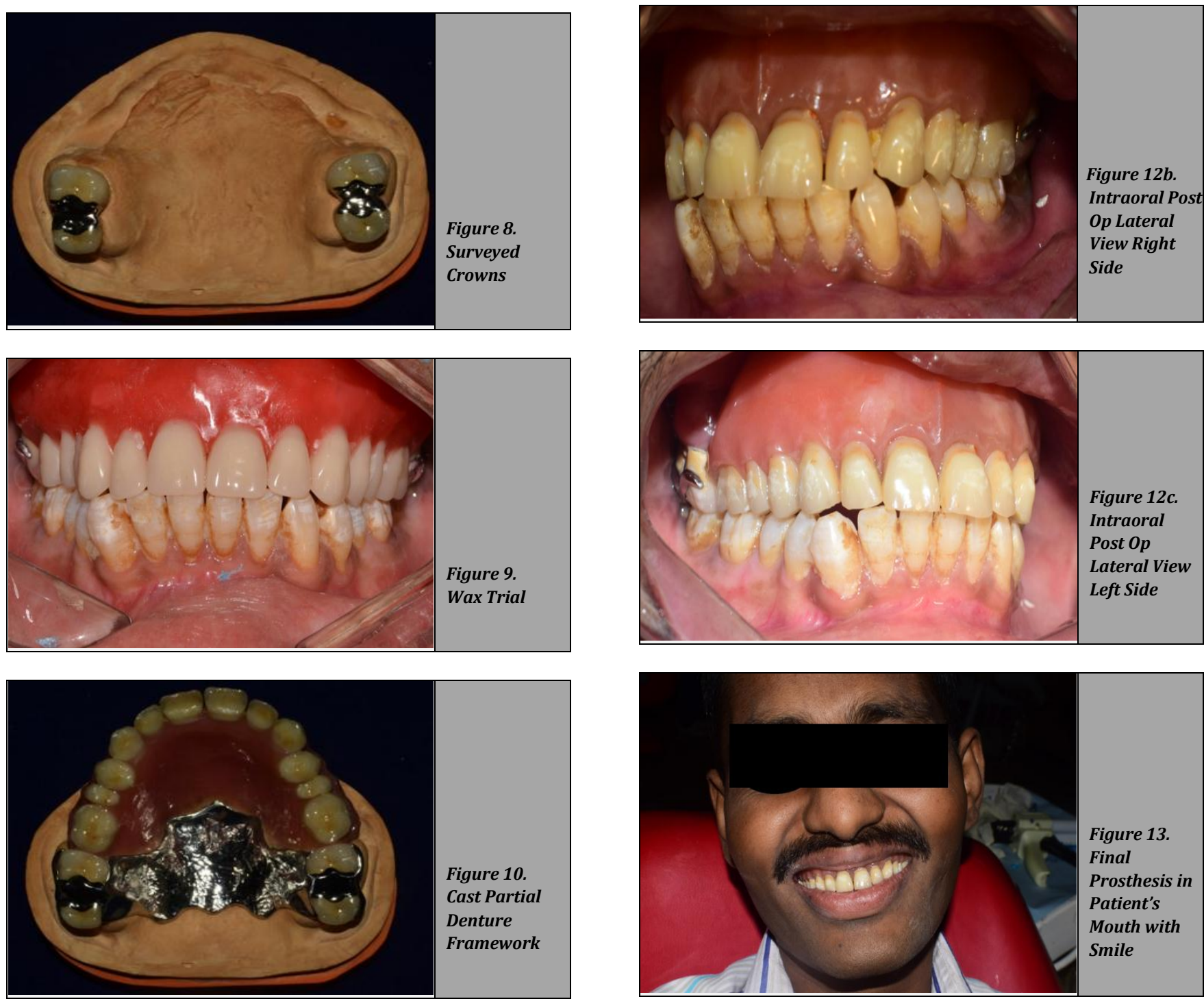

Figure 10.

Cast Partial

Denture

Framework
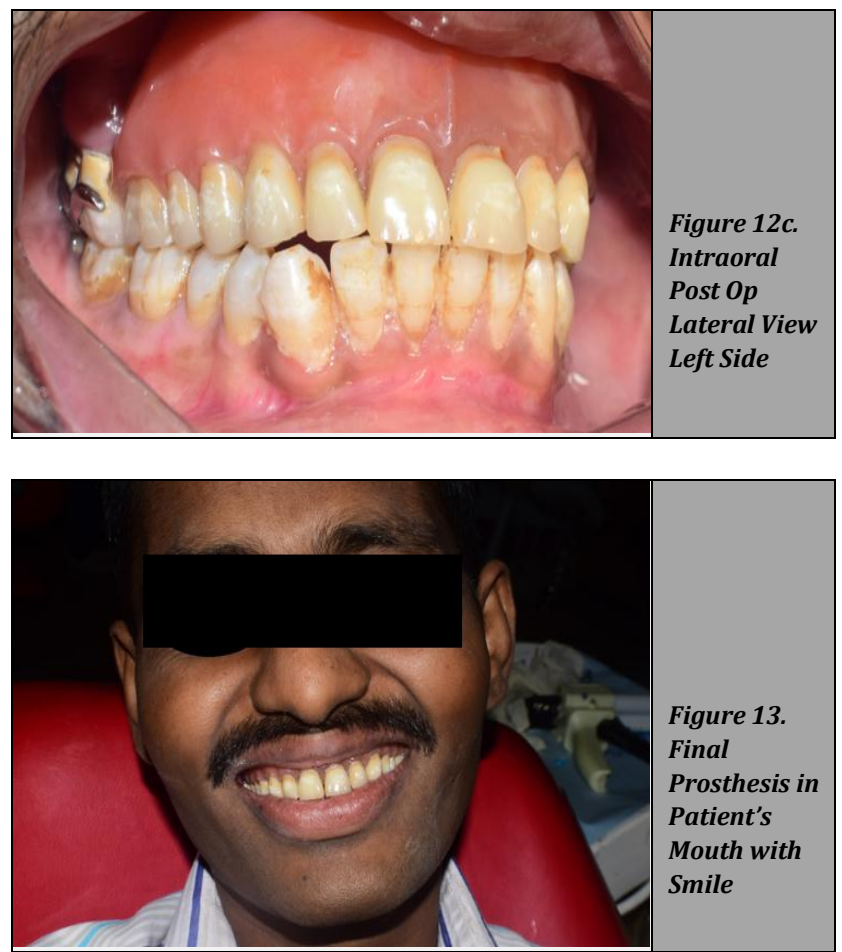


\section{DISCUSSIONS}

The natural teeth have to be preserved as much as possible. Natural teeth preserve alveolar bone from resorption. Bone supports the soft tissue. If the natural teeth is lost, alveolar bone resorption takes place that results in reduced soft tissue support that may cause psychological trauma to the patient. Retaining the remaining natural teeth not only reduces the alveolar bone resorption but also gives retention, stability and support to the prosthesis. Rehabilitation with prosthesis take support form soft tissue structures or hard tissue structures. Hard tissue structures include, bone and teeth. Implants can retain or supports the prosthesis if adequate bone present. If the bone quality and quantity is poor, implants cannot be placed. Tooth supported prosthesis will be the best option since it gives proprioception. If the abutment teeth are less in number or the condition of the abutment teeth to withstand force is less, tooth supported over dentures can be an option. Poor oral hygiene results in decay to the remaining abutment teeth. ${ }^{5,6}$

However, proper oral hygiene maintenance and use of fluoride mouth rinses will preclude the chances of gingivitis and dental caries on abutment teeth underlying over dentures. In this case the design of cast partial over denture resembles the design of mandibular partial over denture supported by implants and posterior natural abutment teeth. ${ }^{6}$ But the differences exist in exclusion of attachments and the support for over denture, which was from underlying natural teeth instead of implants. On the whole there was a definite reduction in the total cost of treatment as implants and precision attachments were not incorporated. There was also an added advantage of preserving patient's own natural teeth and potential benefits of reduced ridge resorption with enhanced retention, stability and support for the prosthesis. Louis and associates reported that patients can masticate food more efficiently with over dentures than with complete dentures which justify the increased cost and time involved in their construction.7,8,9 Moreover prosthesis retained by prefabricated intra-radicular retainers offer greater flexibility with regard to extension of base of prosthesis and the coverage of alveolar ridge in areas of missing teeth. ${ }^{10,11}$ In the present case, clasps engaging the abutment teeth offer additional prosthetic retention.

\section{CONCLUSIONS}

Facial look and teeth are important from an aesthetic point. If teeth and supporting structures are lost, rehabilitating the patient with the prosthesis to an acceptable manner is challenging. A good prosthesis not only rehabilitates the patient's lost function and aesthetics but also gives confidence and comfort in society.

Financial or other competing interests: None.

Disclosure forms provided by the authors are available with the full text of this article at jemds.com.

\section{REFERENCES}

[1] Fenton AH. The decade of overdentures: 1970-1980. J Prosthet Dent 1998;79(1):31-6.

[2] Crum RJ, Rooney GE. Alveolar bone loss in overdentures: a 5 - year study. J Prosthet Dent 1978;40(6):610-3.

[3] Miller PA. Complete dentures supported by natural teeth. J Prosthet Dent 1958;8(6):924-8.

[4] Brill N. Adaptation and the hybrid-prosthesis. J Prosthet Dent 1955;5(6):811-24.

[5] Burns DR. The mandibular complete overdenture. Dent Clin North Am 2004;48(3):603-23.

[6] Ozan 0, Yilmaz B, Pekperdahci T. The prosthodontic rehabilitation of malpositioned implants in a patient with basal cell carcinoma: a clinical report. J Prosthet Dent 2008;99(3):174-7.

[7] Feine JS, Carlsson GE. Implant overdentures: the standard of care for edentulous patients. Illinois: Quintessence Publishing 2003: p. 162.

[8] Basker RM, Davenport JC, Thomason JM. Prosthetic treatment of the edentulous patient. John Wiley \& Sons 2011: p. 288.

[9] Zitzmann NU, Rohner U, Weiger R, et al. When to choose which retention element to use for removable dental prostheses. Int J Prosthodont 2009;22(2):161-7.

[10] Ashok V, Nallaswamy D, Begum SB, et al. Lip bumper prosthesis for an acromegaly patient: a clinical report. J Indian Prosthodont Soc 2014;14(Suppl 1):279-82.

[11] Prakash MS, Ganapathy DM, Nesappan T. Assessment of labial alveolar bone thickness in maxillary central incisor and canine in Indian population using cone-beam computed tomography. Drug Invention Today 2019;11(3):712-4. 